\title{
Loss of $50 \%$ of excess weight using a very low energy diet improves insulin-stimulated glucose disposal and skeletal muscle insulin signalling in obese insulin-treated type 2 diabetic patients
}

\author{
I. M. Jazet • G. Schaart • A. Gastaldelli • E. Ferrannini • \\ M. K. Hesselink • P. Schrauwen • J. A. Romijn •
}

J. A. Maassen • H. Pijl • D. M. Ouwens • A. E. Meinders

Received: 9 August 2007 / Accepted: 13 September 2007 / Published online: 14 December 2007

(C) Springer-Verlag 2007

\begin{abstract}
Aims/hypothesis Both energy restriction (ER) per se and weight loss improve glucose metabolism in obese insulintreated type 2 diabetic patients. Short-term ER decreases basal endogenous glucose production (EGP) but not glucose
\end{abstract}

I. M. Jazet $(\bowtie) \cdot$ A. E. Meinders

Department of General Internal Medicine, C4-r-73, Leiden University Medical Centre,

P.O. Box 9600, 2300 RC Leiden, The Netherlands

e-mail: i.m.jazet@lumc.nl

G. Schaart • M. K. Hesselink • P. Schrauwen

Nutrition and Toxicology Research Institute Maastricht,

University of Maastricht,

Maastricht, The Netherlands

A. Gastaldelli $\cdot$ E. Ferrannini

National Research Centre,

Institute of Clinical Physiology,

University of Pisa School of Medicine,

Pisa, Italy

E. Ferrannini

Department of Internal Medicine,

University of Pisa School of Medicine,

Pisa, Italy

J. A. Romijn · H. Pijl

Department of Endocrinology,

Leiden University Medical Centre,

Leiden, The Netherlands

J. A. Maassen · D. M. Ouwens

Department of Molecular Cell Biology,

Leiden University Medical Centre,

Leiden, The Netherlands disposal. In contrast the blood glucose-lowering mechanism of long-term ER with substantial weight loss has not been fully elucidated. The aim of this study was to investigate the effect of loss of $50 \%$ of excess weight [ $50 \%$ excess weight reduction (EWR)] on EGP, whole-body insulin sensitivity and the disturbed myocellular insulin-signalling pathway in ten obese insulin-treated type 2 diabetic patients.

Methods A euglycaemic-hyperinsulinaemic clamp with stable isotopes $\left(\left[6,6-{ }^{2} \mathrm{H}_{2}\right]\right.$ glucose and $\left[{ }^{2} \mathrm{H}_{5}\right]$ glycerol $)$ combined with skeletal muscle biopsies was performed during a very low energy diet (VLED; $1,883 \mathrm{~kJ} /$ day) on day 2 and again after $50 \%$ EWR. Oral blood glucose-lowering agents and insulin were discontinued 3 weeks prior to the VLED and at the start of the VLED, respectively.

Results Loss of $50 \%$ EWR $(20.3 \pm 2.2 \mathrm{~kg}$ from day 2 to day of $50 \%$ EWR) normalised basal EGP and improved insulin sensitivity, especially insulin-stimulated glucose disposal $\left(18.8 \pm 2.0\right.$ to $39.1 \pm 2.8 \mu \mathrm{mol} \mathrm{kg}$ fat-free $\operatorname{mass}^{-1} \mathrm{~min}^{-1}$, $p=0.001$ ). The latter was accompanied by improved insulin signalling at the level of the recently discovered protein kinase B/Akt substrates AS160 and PRAS40 along with a decrease in intramyocellular lipid (IMCL) content.

Conclusions/interpretation Considerable weight loss in obese, insulin-treated type 2 diabetic patients normalises basal EGP and improves insulin sensitivity resulting from an improvement in insulin signal transduction in skeletal muscle. The decrease in IMCL might contribute to this effect.

Keywords Hyperinsulinaemic-euglycaemic clamp . Insulin resistance $\cdot$ Insulin signalling · Muscle biopsy · Obesity - Type 2 diabetes - Very low calorie diet .

Very low energy diet . Weight loss 


$\begin{array}{ll}\text { Abbreviations } \\ \text { AS160 } & \begin{array}{l}\text { Akt substrate of } 160 \mathrm{kDa} \\ \text { energy restriction }\end{array} \\ \text { ER } & \begin{array}{l}\text { endogenous glucose production } \\ \text { excess weight reduction }\end{array} \\ \text { EWP } & \begin{array}{l}\text { fatty acid transporter } \\ \text { (homologue to human CD36) }\end{array} \\ \text { FAT/CD36 } & \text { fat-free mass } \\ \text { FFM } & \text { fat mass } \\ \text { FM } & \text { hepatic insulin resistance index } \\ \text { HIR } & \text { intramyocellular lipid } \\ \text { IMCL } & \text { metabolic clearance rate of insulin } \\ \text { MCR } & \text { phosphatidylinositol 3'-kinase } \\ \text { PI3K } & \text { protein kinase B/Akt } \\ \text { PKB/Akt } & \text { proline-rich Akt substrate of 40 kDa } \\ \text { PRAS40 } & \text { rate of appearance } \\ R_{\mathrm{a}} & \text { rate of disappearance } \\ R_{\mathrm{d}} & \text { very low energy diet } \\ \text { VLED } & \end{array}$

\section{Introduction}

Insulin resistance is of pivotal clinical importance in obese patients with type 2 diabetes mellitus. Because more than $70 \%$ of insulin-stimulated glucose transport occurs in skeletal muscle [1], skeletal muscle insulin resistance contributes substantially to the metabolic derangements seen in these patients.

In type 2 diabetic patients the impairment in insulinstimulated glucose disposal is due to defects in the insulinsignalling pathway regulating the translocation of GLUT-4 to the cell membrane. Notably, defects in insulin-induced phosphorylation of IRS-1 and phosphatidylinositol 3-kinase (PI3K) [2-4] and in translocation of GLUT-4 to the cell membrane $[5,6]$ have been found in skeletal muscle of patients with type 2 diabetes, whereas, in contrast, total GLUT-4 protein and mRNA levels have repeatedly been shown to be normal $[7,8]$. The involvement of the PI3K substrate protein kinase $\mathrm{B} / \mathrm{Akt}(\mathrm{PKB} / \mathrm{Akt}$ ) in skeletal muscle insulin resistance is less clear, illustrated by studies reporting either normal $[3,9]$ or impaired activation $[10,11]$ by insulin. However, the recently characterised Akt substrate 160 (AS160) $[12,13]$ has been implicated in the link between PKB/Akt activation and GLUT-4 trafficking [14]; also, insulin-mediated AS160 phosphorylation is impaired in skeletal muscle of type 2 diabetic patients [15]. Collectively these studies highlight the importance of the PI3K-PKB/AktAS160-signalling pathway regulating GLUT-4 trafficking.

Energy restriction (ER) and weight loss both improve hyperglycaemia in type 2 diabetic patients. We previously reported that a 2 day very low energy diet [VLED, 1,883 kJ (450 kcal)/day] decreased basal endogenous glucose pro- duction (EGP) in obese insulin-treated type 2 diabetic patients in whom all blood glucose-lowering medication was discontinued [16]. These changes were accompanied neither by an improvement in whole-body peripheral insulin sensitivity nor by changes in insulin signalling, fuel transporter [GLUT-4 and fatty acid transporter homologue to human CD36 (FAT/CD 36)] content and localisation and triacylglycerol content in skeletal muscle [17].

In the present study, we assessed whether a prolonged VLED in obese insulin-treated type 2 diabetic patients leading to substantial weight loss ( $50 \%$ of excess weight) has a different blood glucose-lowering mechanism compared with ER alone (2 day VLED).

\section{Methods}

Patients Ten obese patients with type 2 diabetes mellitus (duration $8 \pm 3$ years), eight women and two men (see patient characteristics in Table 1) participated in this study, which was approved by the Medical Ethical Committee of Leiden University Medical Centre, after giving written informed consent.

Patients had to use at least $30 \mathrm{U}$ insulin/day (mean $94 \pm$ $14 \mathrm{U} /$ day; eight patients also used metformin and two patients used rosiglitazone with the insulin therapy) and had to have a BMI $>30 \mathrm{~kg} / \mathrm{m}^{2}$. In addition, patients had to have remaining endogenous insulin secretion defined as a fasting plasma $\mathrm{C}$ peptide level $>0.27 \mathrm{nmol} / 1$ or a twofold increase of the basal C-peptide level after administration of $1 \mathrm{mg}$ glucagon i.v.

Patients also had to have stable bodyweight for at least 3 months and were instructed not to alter lifestyle habits from screening until the start of the study.

Diet and protocol outline Three weeks before the start of the study, all oral blood glucose-lowering medication was discontinued. At day -1 only short-acting insulin was given, whereas evening doses of intermediate- and longacting insulin were omitted. On day 0 , patients started a VLED $(1,883 \mathrm{~kJ} /$ day $)$ consisting of three sachets of Modifast (Nutrition \& Santé, Antwerp, Belgium) per day, providing about $50 \mathrm{~g}$ protein, 50-60 g carbohydrate, 7-9 g lipid and $10 \mathrm{~g}$ dietary fibre. Insulin therapy remained stopped from the start of the VLED onwards. After $48 \mathrm{~h}$ of the VLED, patients were admitted to the research centre for the metabolic studies (day 2) as outlined below. After this study day patients continued the VLED until they had lost $50 \%$ of their excess weight (see Results), then the second study day took place (day of $50 \%$ excess weight reduction, EWR) (Fig. 1).

During the VLED patients visited the research centre weekly for support to keep up with their diet, confirmation of compliance and measurement of bodyweight, WHR, 
Table 1 Patient characteristics and body composition parameters before and after 2 days of a VLED and again at 50\% EWR with the VLED

\begin{tabular}{llll}
\hline & Before VLED & Day 2 VLED & $50 \%$ EWR \\
\hline Age (years) & $55 \pm 3$ & - & \\
BMI $\left(\mathrm{kg} / \mathrm{m}^{2}\right)$ & $40.2 \pm 1.6$ & $39.7 \pm 1.7^{\mathrm{b}}$ & - \\
Weight $(\mathrm{kg})$ & $113.0 \pm 7.1$ & $110.9 \pm 6.9^{\mathrm{c}}$ & $32.3 \pm 1.2^{\mathrm{d}}$ \\
FM (kg) & $51.0 \pm 3.9$ & $50.1 \pm 3.7$ & $90.6 \pm 0.5^{\mathrm{d}}$ \\
Waist circumference (cm) & $126.8 \pm 3.3$ & $126.2 \pm 3.5$ & $32.7 \pm 3.0^{\mathrm{d}}$ \\
Fasting plasma glucose (mmol/l) & $11.1 \pm 0.8$ & $12.5 \pm 0.5$ & $107.7 \pm 3.3^{\mathrm{d}}$ \\
Fructosamine (nmol/l) & $\left(\mathrm{HbA}_{1 \mathrm{c}} 7.7 \pm 0.4 \%\right)$ & $329 \pm 11$ & $7.8 \pm 0.5^{\mathrm{d}}$ \\
Fasting serum insulin (pmol/l) & $-^{\mathrm{a}}$ & $168 \pm 2.2$ & $283 \pm 12^{\mathrm{e}}$ \\
Units of insulin (U/day) & $94 \pm 14$ & 0 & $106 \pm 9^{\mathrm{f}}$ \\
\hline
\end{tabular}

Data are means \pm SEM

${ }^{a}$ Values likely to be unreliable because patients had used short-acting insulin therapy until the evening before

${ }^{\mathrm{b}} p=0.049,{ }^{\mathrm{c}} p=0.0001$ day 2 compared with day 0

${ }^{\mathrm{d}} p=0.0001$ compared with both before VLED and day 2 VLED

${ }^{\mathrm{e}} p=0.035,{ }^{\mathrm{f}} p=0.001$ day of $50 \%$ EWR compared with day 2 VLED

blood pressure and blood glucose regulation. No blood glucose-lowering agents were used during this period.

Assessments of body composition On both study days, body fat mass (FM) and fat-free mass (FFM) were measured by bioelectrical impedance analysis (Bodystat 1500; Bodystat, Douglas, Isle of Man, UK).

Length $(\mathrm{m})$ and weight $(\mathrm{kg})$, BMI and waist circumference were measured according to $\mathrm{WHO}$ recommendations.

Metabolic studies Metabolic studies were performed as described previously [17]. In short, basal rates of glucose and glycerol turnover were assessed after $3 \mathrm{~h}$ of an adjusted primed $[17.6 \mu \mathrm{mol} / \mathrm{kg} \times$ actual plasma glucose concentration $(\mathrm{mmol} / \mathrm{l}) / 5$ (normal plasma glucose)] continuous $\left(0.33 \mu \mathrm{mol} \mathrm{kg}{ }^{-1} \mathrm{~min}^{-1}\right)$ infusion of $\left[6,6-{ }^{2} \mathrm{H}_{2}\right]$ glucose (enrichment 99.9\%; Cambridge Isotopes, Cambridge, MA, USA) and $1.5 \mathrm{~h}$ of a primed $(1.6 \mu \mathrm{mol} / \mathrm{kg})$ continuous $\left(0.11 \mu \mathrm{mol} \mathrm{kg}{ }^{-1} \mathrm{~min}^{-1}\right)$ infusion of $\left[{ }^{2} \mathrm{H}_{5}\right]$ glycerol (Cambridge Isotopes). Subsequently, insulin-stimulated rates of glucose and glycerol turnover were measured after $4.5 \mathrm{~h}$ of a hyperinsulinaemic-euglycaemic clamp (Actrapid; Novo Nordisk Pharma, Alphen aan de Rijn, the Netherlands; rate $40 \mathrm{mU} \mathrm{m}^{-2} \mathrm{~min}^{-1}$ ). Glucose values were clamped at $5 \mathrm{mmol} / \mathrm{l}$ via the infusion of a variable rate of $20 \%$ glucose enriched with $3 \%\left[6,6{ }^{2} \mathrm{H}_{2}\right]$ glucose.

Basal and insulin-stimulated glucose and lipid oxidation rates [18] were determined by indirect calorimetry with a ventilated hood (Oxycon Beta; Mijnhardt Jaegher, Breda, the Netherlands).

Blood chemistry Serum insulin was measured with an immunoradiometric assay (Biosource, Nivelles, Belgium). Serum C-peptide and glucagon levels were measured with an RIA from Linco Research (St Charles, MO, USA). Growth hormone was measured with a time-resolved immunofluorescent assay (Wallac, Turku, Finland) specific for the $22 \mathrm{kDa}$ growth hormone. Cortisol was measured with an RIA (Sorin Biomedica, Milan, Italy). Serum triacylglycerol was measured with a fully automated Modular P 800 and fructosamine with a Modular I 800 system, both from Hitachi (Tokyo, Japan).
Fig. 1 Protocol outline. See text for explanation

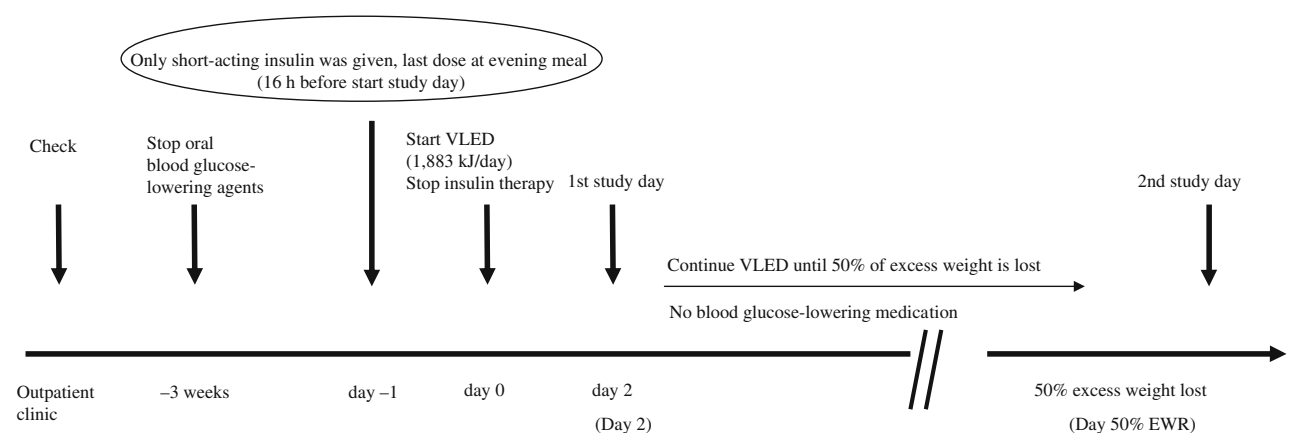


Serum NEFAs were measured using the enzymatic colorimetric acyl-CoA synthase/acyl-CoA oxidase assay (Wako Chemicals, Neuss, Germany). Serum glucose and $\left[6,6-{ }^{2} \mathrm{H}_{2}\right]$ glucose as well as serum glycerol and $\left[{ }^{2} \mathrm{H}_{5}\right]$ glycerol were determined in a single analytical run, using GC-MS as described previously [19].

Muscle biopsies Muscle biopsies were taken from the vastus lateralis muscle in the basal situation and $30 \mathrm{~min}$ after the start of the insulin infusion $[17,20]$ using a modified Bergström needle under localised anaesthesia with $1 \%$ lidocaine. Muscle samples were snap-frozen in liquid nitrogen-cooled isopentane and stored at $-80^{\circ} \mathrm{C}$ until further analysis.

Insulin signalling Muscle biopsies were homogenised in PI3K lysis buffer using an Ultraturrax mixer and centrifuged $\left(15 \mathrm{~min} ; 16,100 \times g ; 4^{\circ} \mathrm{C}\right)$, then protein content was determined using a BCA kit (Pierce, Rockford, IL, USA) [21]. IRS-1 was immunoprecipitated overnight $\left(4^{\circ} \mathrm{C}\right)$ from $1.5 \mathrm{mg}$ protein using IRS-1 antibody $\mathrm{K} 6$, and PI3K activity was determined as described previously [21].

In addition, proteins ( $25 \mu \mathrm{g}$ per lane) were separated by SDS-PAGE and blotted on polyvinylidene difluoride membranes (Millipore, Bedford, MA, USA). Filters were incubated overnight $\left(4^{\circ} \mathrm{C}\right)$ with IRS-1 K6 and Akt-1 antibody (Upstate, Lake Placid, NY, USA), anti-phosphoproline rich Akt substrate 40-Thr246 (\#44-100G), antiphospho-AS160 (\#44-1071G) (Biosource International, Camarillo, CA, USA) and anti-AS160/TBC1D4 antibody (Abcam, Cambridge, UK). Bound antibodies were detected using appropriate horseradish peroxidase-conjugated secondary antibodies (Promega, Madison, WI, USA) at a 1:10,000 dilution, followed by visualisation by enhanced chemiluminescence. Blots were quantified by densitometric analysis of the films using Scion Image beta 4.02 software (Scion, Frederick, MD, USA).

Oil Red $O$ staining Tissue sections of basal biopsies were stained with Oil Red O combined with a doubleimmunofluorescence assay (anti-laminin and a monoclonal antibody raised against adult human slow myosin heavy chain) to allow quantification of intramyocellular lipids (IMCLs) as described before [22].

Oil Red O epifluorescence signal was quantified for each muscle cell of each cross section. Lipid droplet density was calculated by dividing the total number of droplets by the total IMCL area measured [22].

Western blotting for FAT/CD36 and GLUT-4 For Western blotting analyses, muscle membrane fractions and total muscle protein fractions were prepared as described before for GLUT-4 [23] and fatty acid transporter homologue to human CD36 (FAT/CD36) $[17,24]$ in biopsies taken during the insulin-stimulated situation.

Blots were incubated with the polyclonal GLUT-4-BW antibody [23] or the MO25 monoclonal antibody specific for FAT/CD36 [24]. Protein bands were detected and quantified with an Odyssey Infrared Imager (Li-Cor Biosciences, Westburg BV, Leusden, The Netherlands).

Calculations A physiological and isotopic steady-state was achieved during the last $30 \mathrm{~min}$ of the basal period and the insulin-infusion period, therefore the rates of appearance $\left(R_{\mathrm{a}}\right)$ and disappearance $\left(R_{\mathrm{d}}\right)$ for glucose and glycerol were calculated as the tracer infusion rate divided by the tracer-to-tracee ratio [25]. Glucose flux rates were expressed per kg FFM, whereas glycerol flux rates were normalised per kg FM.

EGP during the basal steady-state is equal to the $R_{\mathrm{a}}$ of glucose, whereas EGP during the clamp was calculated as the difference between $R_{\mathrm{a}}$ and the glucose infusion rate. Since the fasting plasma insulin concentration is a strong inhibitory stimulus for EGP, the basal hepatic insulin

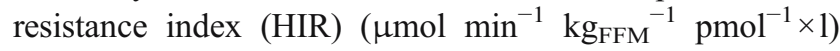
was calculated as the product of fasting EGP and fasting plasma insulin concentration. Experimental validation for the use of this index has been published [26, 27]. The metabolic clearance rate of insulin $\left(\mathrm{MCR}_{\mathrm{I}}\right)$ was calculated as the constant infusion rate of insulin divided by the steady-state serum insulin concentration corrected for endogenous insulin secretion [28].

Total lipid and carbohydrate oxidation rates were calculated as described by Simonson and DeFronzo [18]. Non-oxidative glucose metabolism was calculated by subtracting the glucose oxidation rate (determined by indirect calorimetry) from glucose $R_{\mathrm{d}}$.

Percentage excess weight was calculated as: $100 \times($ weight/ ideal bodyweight) -100 . Ideal bodyweight for height was determined according to the 1983 Metropolitan Life Insurance tables (Metropolitan Life Insurance Company, New York, USA).

Statistical analysis Data are presented as means \pm SEM. Differences between day 2 and day of $50 \%$ EWR, as well as differences between basal and insulin-stimulated biopsies were analysed by the Student's $t$ test for paired samples. Nonparametric (Wilcoxon signed-rank test) tests for paired samples were performed when appropriate. Correlation analysis was carried out using Pearson's correlation. All analyses were performed using SPSS for Windows version 12.0 (SPSS, Chicago, IL, USA). Significance was accepted at $p<0.05$. 


\section{Results}

Weight and body composition Weight loss during the first 2 days (day 0 to day 2) was $-2.1 \pm 0.3 \mathrm{~kg}$. From day 2 until the second study day, patients lost an additional $20.3 \pm$ $2.2 \mathrm{~kg}(p=0.0001), 85 \%$ of which was FM (Table 1). BMI decreased from $39.7 \pm 1.7 \mathrm{~kg} / \mathrm{m}^{2}$ on day 2 to $32.3 \pm$ $1.2 \mathrm{~kg} / \mathrm{m}^{2}$ on the day of $50 \% \operatorname{EWR}(p=0.0001)$. Mean time to $50 \%$ EWR was 17 weeks (range 4-35 weeks). The duration of time to $50 \%$ EWR was strongly and significantly positively correlated with bodyweight and body FM on day 0 . There was no relationship between time to $50 \%$ EWR and any measure of insulin sensitivity or change in insulin sensitivity.

Fasting plasma glucose and insulin concentration Fasting plasma glucose levels dropped significantly from day 2 to day of $50 \% \operatorname{EWR}(12.5 \pm 0.5$ to $7.8 \pm 0.5 \mathrm{mmol} / 1, p=0.0001)$, as did serum insulin concentrations (from $168 \pm 15$ to $106 \pm$ $9 \mathrm{pmol} / \mathrm{l}, p=0.001)$.

Serum fructosamine levels declined from $329 \pm 11$ to $283 \pm$ $12 \mathrm{nmol} / \mathrm{l}(p=0.035$; Table 1$)$.

EGP and whole-body glucose disposal On both study days, plasma glucose was clamped at identical levels $(5.1 \pm 0.3$ and $5.4 \pm 0.3 \mathrm{mmol} / 1$ on day 2 and day of $50 \% \mathrm{EWR}$, respectively, $p=\mathrm{NS}$ ). The degree of exogenous hyperinsulinaemia was lower on the day of $50 \%$ EWR $(561 \pm 28 \mathrm{pmol} / \mathrm{l})$ compared with day $2(626 \pm 23 \mathrm{pmol} / 1, p=0.023)$, despite equal insulin infusion rates $\left(40 \mathrm{mU} \mathrm{m}^{-2} \mathrm{~min}^{-1}\right)$. This was the result of the increased $\mathrm{MCR}_{\mathrm{I}}$ (Table 2).

Basal EGP decreased $\sim 20 \%$ from day 2 to the day of $50 \%$ EWR and insulin suppression of EGP also was significantly stronger on the day of $50 \%$ EWR in absolute terms. Consequently, the HIR was significantly lower on the day of $50 \%$ EWR than on day 2 under both basal and insulinised conditions (Table 2).

Of the hormones involved in the regulation of EGP, fasting serum cortisol and glucagon concentrations did not change with weight loss, whereas fasting growth hormone levels increased as expected (Table 2).

Insulin-stimulated glucose disposal increased 107\% from day 2 to the day of $50 \%$ EWR. If we correct for the difference in clamp serum insulin levels between study days by dividing glucose $R_{\mathrm{d}}$ by the clamp serum insulin levels, the difference in peripheral insulin sensitivity between study days becomes even more significant (0.03 vs $0.07 \mu \mathrm{mol}$ $\left.\min ^{-1} \mathrm{~kg}_{\mathrm{FFM}}{ }^{-1} \mathrm{pmol}^{-1} \times 1, p=0.0001\right)$.

Glycerol $\mathrm{R}_{a}$ and NEFAs, glycerol and triacylglycerol Basal glycerol $R_{\mathrm{a}}$ decreased by $35 \%$ between study days. Exogenous insulin failed to suppress glycerol $R_{\mathrm{a}}$ on day 2 but did so on the day of $50 \%$ EWR, to levels that were significantly different from day 2 (Table 2). Accordingly, fasting levels of

Table 2 Metabolic parameters during a VLED on day 2 and at $50 \%$ EWR

\begin{tabular}{|c|c|c|c|c|c|c|}
\hline & \multicolumn{3}{|l|}{ Day 2} & \multicolumn{3}{|c|}{ Day of $50 \%$ EWR } \\
\hline & Basal & Clamp & $p$ value & Basal & Clamp & $p$ value \\
\hline Glucose $R_{\mathrm{d}}\left(\mu \mathrm{mol} \mathrm{kg} \mathrm{FFM}^{-1} \min ^{-1}\right)$ & $20.0 \pm 0.9$ & $18.8 \pm 2.0$ & NS & $16.4 \pm 1.2^{\mathrm{c}}$ & $39.1 \pm 2.8^{\mathrm{c}}$ & 0.001 \\
\hline Glucose Ox $\left(\mu \mathrm{mol} \mathrm{kg} \mathrm{FFM}^{-1} \min ^{-1}\right)$ & $6.7 \pm 1.4$ & $6.1 \pm 0.9$ & NS & $4.2 \pm 0.4$ & $12.7 \pm 1.5^{\mathrm{b}}$ & 0.001 \\
\hline NOGD $\left(\mu \mathrm{mol} \mathrm{kg} \mathrm{FFM}^{-1} \min ^{-1}\right)$ & $14.8 \pm 1.1$ & $12.2 \pm 1.6$ & NS & $12.4 \pm 1.1^{\mathrm{a}}$ & $27.7 \pm 2.8^{\mathrm{b}}$ & 0.005 \\
\hline $\operatorname{EGP}\left(\mu \mathrm{mol} \mathrm{kg} \mathrm{FFM}^{-1} \min ^{-1}\right)$ & $20.0 \pm 0.9$ & $8.5 \pm 0.9$ & 0.0001 & $16.4 \pm 1.2^{\mathrm{c}}$ & $4.6 \pm 1.2^{\mathrm{b}}$ & 0.0001 \\
\hline $\operatorname{HIR}\left(\mu \mathrm{mol} \mathrm{kg} \mathrm{FFM}^{-1} \min ^{-1} \mathrm{pmol}^{-1} \times 1\right)$ & $3,319 \pm 245$ & $5,251 \pm 500$ & 0.005 & $1,729 \pm 193^{d}$ & $2,511 \pm 633^{\mathrm{c}}$ & NS \\
\hline Glycerol $R_{\mathrm{a}}\left(\mu \mathrm{mol} \mathrm{kg} \mathrm{FM}^{-1} \min ^{-1}\right)$ & $16.4 \pm 2.3$ & $11.5 \pm 2.3$ & NS & $14.6 \pm 1.4$ & $7.5 \pm 1.6$ & 0.012 \\
\hline Lipid Ox $\left(\mu \mathrm{mol} \mathrm{kg} \mathrm{FFM}^{-1} \min ^{-1}\right)$ & $8.0 \pm 0.5$ & $8.3 \pm 0.3$ & NS & $7.1 \pm 0.5$ & $5.5 \pm 0.8^{\mathrm{c}}$ & 0.011 \\
\hline $\mathrm{MCR}_{\mathrm{I}}\left(\mathrm{ml} \mathrm{m}^{-2} \min ^{-1}\right)$ & - & $0.47 \pm 0.02$ & - & - & $0.53 \pm 0.03^{\mathrm{a}}$ & - \\
\hline Glucose $(\mathrm{mmol} / \mathrm{l})$ & $12.5 \pm 0.5$ & $5.1 \pm 0.3$ & 0.0001 & $7.8 \pm 0.5^{\mathrm{d}}$ & $5.4 \pm 0.3$ & 0.003 \\
\hline Plasma insulin (pmol/1) & $168 \pm 15$ & $626 \pm 23$ & 0.0001 & $106 \pm 9^{\mathrm{c}}$ & $561 \pm 28^{\mathrm{a}}$ & 0.0001 \\
\hline Glycerol (mmol/1) & $150 \pm 15$ & $114 \pm 18$ & NS & $108 \pm 12^{\mathrm{c}}$ & $65 \pm 12^{\mathrm{a}}$ & 0.011 \\
\hline NEFA (mmol/l) & $1.6 \pm 0.2$ & $1.1 \pm 0.3$ & NS & $1.2 \pm 0.1^{\mathrm{a}}$ & $0.3 \pm 0.1^{\mathrm{a}}$ & 0.012 \\
\hline Triacylglycerol (mmol/l) & $2.7 \pm 0.5$ & $2.5 \pm 0.5$ & NS & $1.2 \pm 0.1^{\mathrm{c}}$ & $0.9 \pm 0.1^{\mathrm{a}}$ & 0.0001 \\
\hline Cortisol (nmol/1) & $451 \pm 30$ & $404 \pm 49$ & NS & $419 \pm 34$ & $232 \pm 31^{\mathrm{b}}$ & 0.001 \\
\hline Glucagon (ng/l) & $63.2 \pm 8.3$ & $86.6 \pm 15.0$ & NS & $70.7 \pm 5.1$ & $38.9 \pm 2.7$ & 0.001 \\
\hline Growth hormone (mU/l) & $1.2 \pm 0.4$ & $4.0 \pm 1.5$ & 0.002 & $3.7 \pm 1.5$ & $2.4 \pm 0.9$ & NS \\
\hline
\end{tabular}

Data are means \pm SEM

${ }^{\mathrm{a}} p<0.05,{ }^{\mathrm{b}} p<0.01,{ }^{\mathrm{c}} p<0.001,{ }^{\mathrm{d}} p<0.0001$ for day 2 vs day of $50 \%$ EWR

To convert insulin from $\mathrm{pmol} / \mathrm{l}$ to $\mathrm{mU} / 1$ divide by 6.945

NOGD, non-oxidative glucose disposal; Ox, oxidation 
NEFAs, triacylglycerol and glycerol declined significantly, and clamp values of serum NEFA and glycerol all declined between study days both in the fasting state and in response to euglycaemic hyperinsulinaemia, reflecting a better suppressibility of lipolysis by insulin (Table 2).

Glucose and lipid oxidation rates On the day of 50\% EWR, insulin infusion increased the rate of glucose oxidation significantly compared with day 2 . Basal as well as insulin-stimulated non-oxidative glucose disposal also increased significantly after weight loss. The ability of insulin to suppress lipid oxidation was improved with weight loss (Table 2).

Insulin signalling in skeletal muscle biopsies Absolute levels of insulin-stimulated IRS-1-associated PI3K were not different between both study days but the increase over basal was significant after weight loss because of lower basal levels ( $p=0.01$, Fig. 2a, Table 3 ). To corroborate this finding, we also assessed the phosphorylation of two more distal components of the insulin-signalling system, i.e. the recently identified PKB/Akt substrates AS160 and prolinerich Akt substrate 40 (PRAS40). Basal as well as insulinstimulated AS160 and PRAS40 phosphorylation, corrected for protein content, were significantly higher after weight loss compared with day 2 of the VLED (Fig. 2b,c and Table 3). On the day of $50 \%$ EWR, insulin-stimulated glucose disposal correlated significantly with absolute levels of AS160, which is a well-defined intermediate in GLUT-4 translocation, as well as the difference between basal and clamp (i.e. delta) AS160. The correlation with delta PI3K just failed to reach significance $(r=0.69, p=0.059)$.

Effect of weight loss on the fuel transporters GLUT-4 and FAT/CD36 Weight reduction had no statistically significant effect on the abundance of the fuel transporters GLUT-4 (Fig. 3) and FAT/CD36 (data not shown) at the plasma membrane following hyperinsulinaemia despite the fact that seven out of the ten patients showed a higher GLUT-4 density at the cell membrane after weight loss.

IMCL content as assessed with an Oil Red O staining Oil red $\mathrm{O}$ staining showed a reduction in IMCL after weight loss, in both type I and type II muscle fibres (Fig. 4). Type I muscle fibres, stained with the antibody against human slow myosin heavy chain, contained significantly more IMCL on either study day compared with the unstained type II muscle fibres (Fig. 5a). The percentage of type I fibres did not change with weight loss (Fig. 5b). Interestingly, time to 50\% EWR correlated negatively with the number of type I fibres at the start of the diet (day 2), $r=-0.64, p=0.046$. The amount of IMCL correlated positively with lipid oxidation $(r=0.74, p=$ $0.024)$ and negatively with whole-body insulin-stimulated
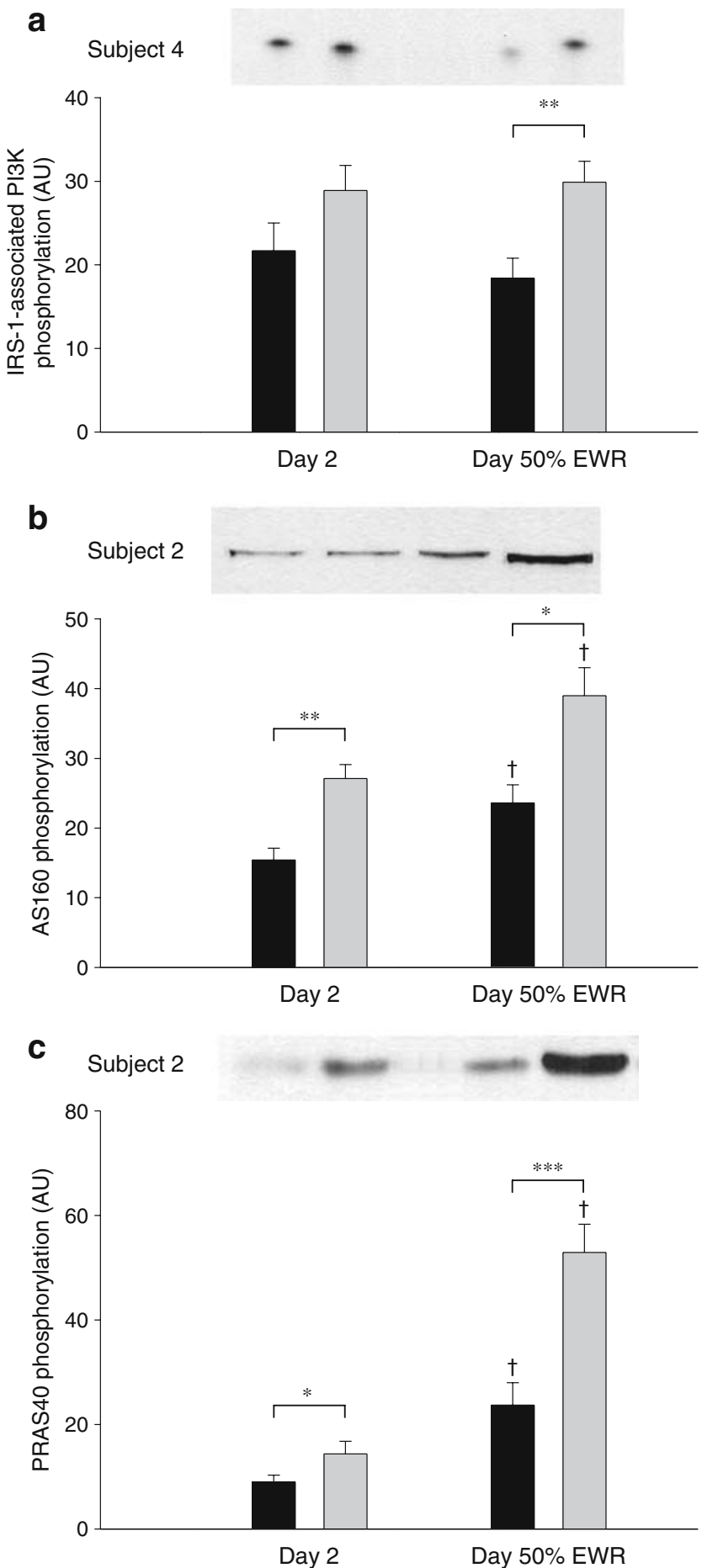

Fig. 2 Representative immunoblots (upper sections) and quantification [arbitrary units (AU), means \pm SEM] (lower sections) of IRS-1associated PI3K activity (a), AS160 phosphorylation (b) and PRAS40 phosphorylation (c) in vastus lateralis muscle biopsies obtained on day 2 of a VLED and at 50\% EWR in basal (black bars) and hyperinsulinaemic-euglycaemic conditions (grey bars). Note that for IRS-1-associated PI3K activity only insulin-stimulated increase over basal is significant on the day of $50 \%$ EWR, whereas AS160 phosphorylation and PRAS40 phosphorylation both show absolute increases in the basal and insulin-stimulated situation after weight loss. $* p<0.05, * * p<0.01, * * * p<0.001$ clamp vs basal. ${ }^{\dagger} p<0.05$ day of $50 \%$ EWR compared with day 2, basal as well as insulin-stimulated 
Table 3 Activity levels of measured insulin-signalling molecules

\begin{tabular}{|c|c|c|c|c|c|c|}
\hline & \multicolumn{3}{|l|}{ Day 2} & \multicolumn{3}{|c|}{ Day of $50 \%$ EWR } \\
\hline & Basal & Clamp & $p$ value & Basal & Clamp & $p$ value \\
\hline IRS-1-associated PI3K activity & $21.7 \pm 3.3$ & $28.9 \pm 3.0$ & NS & $18.4 \pm 2.4$ & $29.9 \pm 2.5$ & 0.01 \\
\hline AS160 phosphorylation & $15.4 \pm 1.7$ & $27.1 \pm 2.0$ & 0.008 & $23.6 \pm 2.6^{\mathrm{a}}$ & $39.0 \pm 4.0^{\mathrm{a}}$ & 0.02 \\
\hline PRAS40 phosphorylation & $9.0 \pm 1.1$ & $23.7 \pm 4.2$ & 0.016 & $14.4 \pm 2.4^{\mathrm{b}}$ & $52.9 \pm 5.4^{\mathrm{c}}$ & 0.001 \\
\hline
\end{tabular}

Data are means \pm SEM

Data are corrected for protein expression levels and are expressed in arbitrary units (see Methods)

${ }^{\mathrm{a}} p=0.026,{ }^{\mathrm{b}} p=0.046,{ }^{\mathrm{c}} p=0.018$ for day 2 vs day of $50 \%$ EWR

glucose disposal $(r=-0.63, p=0.049)$ on the day of $50 \%$ EWR. On the other hand, the change in IMCL did not correlate with change in bodyweight, glucose or lipid metabolism, insulin signalling or FAT/CD36 content.

\section{Discussion}

Compared with short-term ER (2 day VLED), which only affects basal EGP [16, 17], long-term ER leading to 50\% EWR reduced basal EGP and improved insulin sensitivity of the liver, adipose tissue and skeletal muscle in obese, insulin-treated type 2 diabetic patients. These effects occurred despite the fact that patients had been taken off all blood glucose-lowering medication (including insulin) during the VLED and were still obese at the end of the $\operatorname{VLED}\left(\mathrm{BMI}=32.3 \mathrm{~kg} / \mathrm{m}^{2}\right)$.

Insulin-stimulated glucose disposal improved by $\sim 100 \%$. This is comparable with the improvements seen in obese nondiabetic patients in whom restrictive bariatric surgery was used to induce weight loss: an increase in $M$ value from 7-19 to $\sim 35 \mu \mathrm{mol} \mathrm{kg} \mathrm{FFM}^{-1} \min ^{-1}[29,30]$ compared with the increase (from $9.9 \pm 2.3$ to $37.2 \pm 4.6 \mu \mathrm{mol} \mathrm{kg}_{\mathrm{FFM}}{ }^{-1} \mathrm{~min}^{-1}$ ) seen in our patients. In skeletal muscle this increase in

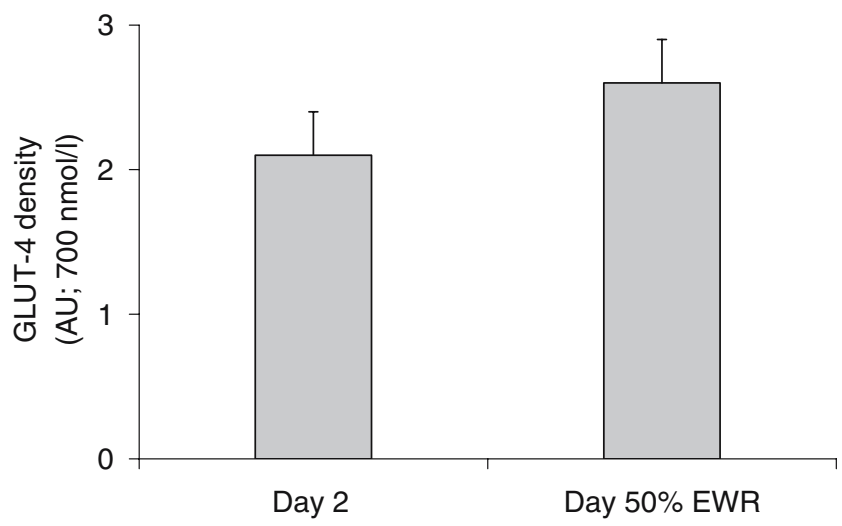

Fig. 3 Quantification of GLUT-4 (AU, arbitrary units) at the cell membrane during insulin-stimulated conditions on day 2 of a VLED and at $50 \%$ EWR. Data are means \pm SEM. Changes between study days were not significant insulin-stimulated glucose disposal was reflected in increased insulin signalling at the level of two recently discovered downstream components of PKB/AKT: AS160 and PRAS40, whereas IRS-1-associated PI3K activity showed no difference in absolute levels, although the increase over basal was significant after weight loss. Insulin-stimulated phosphorylation of AS160 is linked to GLUT-4 translocation and has previously been reported to be disturbed in skeletal muscle of moderately obese $\left(\mathrm{BMI}=27 \mathrm{~kg} / \mathrm{m}^{2}\right)$ type 2 diabetic patients with relatively mild diabetes [15]. We did not study control individuals and cannot therefore compare insulinstimulated AS160 phosphorylation in our patients with that of healthy lean individuals. However, our patients were more obese $\left(\mathrm{BMI}=40.2 \pm 1.6 \mathrm{~kg} / \mathrm{m}^{2}\right)$ and insulin-resistant than the patients in the study mentioned above [15]. Nonetheless, we found that insulin had a significant effect on AS160 phosphorylation on both study days and that weight reduction enhances insulin-stimulated AS160 phosphorylation. To the best of our knowledge these findings have not been described before.

The similar absolute levels of insulin-stimulated IRS-1associated PI3K activity after weight loss were unexpected in light of the increase of the more distal signalling components, and we have no good explanation for it. It might be, although unlikely [20], that the timing of the biopsy was such that levels were already declining while those of PRAS40 and AS160 were still rising. Alternatively, there might be no 1:1 relationship between PI3K and AS160 or PRAS40, as was shown for activation of IRS-1 and PI3K [2]. Furthermore, it might be that these were the maximal possible insulin-stimulated PI3K values for this particular patient group (obese type 2 diabetic patients with advanced disease who were still obese at the end of the study), but we did not study a dose-effect curve [4, 20]. Perhaps more likely, given the fact that interventions with thiazolidinediones [31, 32] and exercise [33] also show discrepancies between improvement of whole-body insulin-stimulated glucose disposal and no effect on PI3K activation, is that there is another activation route of $\mathrm{PI} 3 \mathrm{~K}-\mathrm{PKB} / \mathrm{Akt}-\mathrm{AS} 160$. Finally, the increase of insulin-stimulated PI3K activity over basal could still have played a role. However, this is unclear from our results and for now we have insufficient arguments 

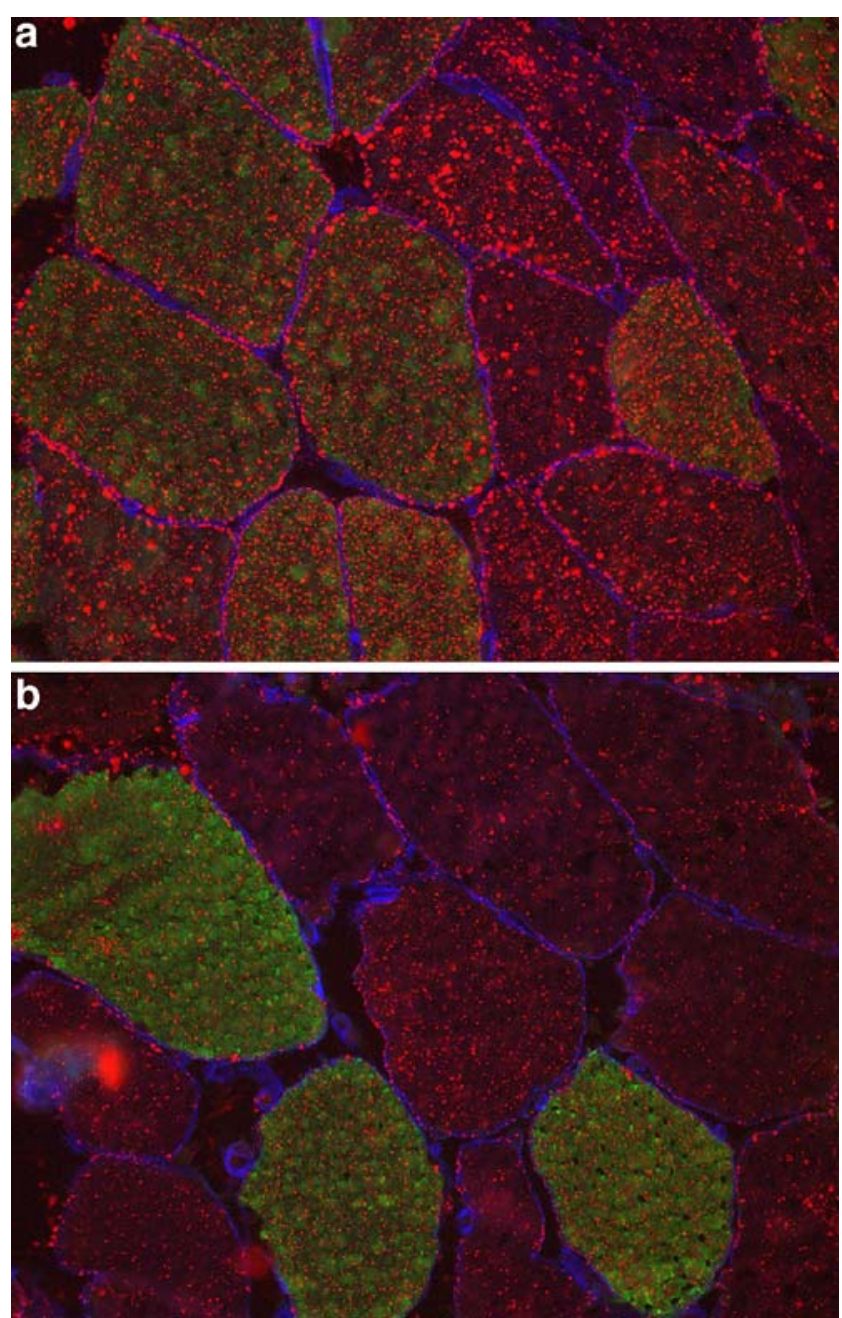

Fig. 4 Oil Red O staining (red) in combination with myosin heavy chain type 1 immunofluorescence (green) and laminin staining (blue) in cryosections of vastus lateralis muscle on day 2 of a VLED (a) and at $50 \%$ EWR (b). Note the decrease in intramyocellular triacylglycerol content on the day of $50 \%$ EWR shown in Fig. $5 \mathrm{~b}$

for a role of PI3K in the improvement of insulin-stimulated glucose disposal.

Notably, we observed, also for the first time, that weight reduction significantly increases insulin-stimulated PRAS40 phosphorylation, another substrate for PKB/Akt. PRAS40 has been identified as a component of the mammalian target of rapamycin (mTOR) nutrient-sensing pathway, whose activity is deregulated in rodent models of insulin resistance $[34,35]$. Although the physiological function of PRAS40 in insulin action is not completely clear, we recently observed that phosphorylation of this protein is induced by physiological hyperinsulinaemia in insulin target tissues, and is blunted under conditions of high fat diet-induced insulin resistance [36]. Whether the improvement in insulinstimulated PRAS40 phosphorylation also relates to mTOR and whether it can be ascribed to weight loss and/or ER will be the subject of further studies.
Remarkably, the improvement in insulin signalling was not accompanied by a significant improvement in GLUT-4 translocation to the cell membrane. Others have also reported a dissociation between insulin-stimulated glucose disposal and improvement in either insulin signalling and/ or GLUT-4 content at the cell membrane. Ryder et al. [5] found that although insulin-stimulated glucose disposal was $50 \%$ lower in patients with type 2 diabetes compared with lean control individuals, insulin-stimulated cell surface GLUT-4 content over basal was only $10 \%$ that of healthy controls. In another study, Karlsson et al. found a significant, 36\% improvement in insulin-stimulated wholebody glucose uptake after 26 weeks of treatment with rosiglitazone in newly diagnosed type 2 diabetic patients; this change, however, was not accompanied by improved signalling of IRS-1-associated PI3K, PKB/AKT or AS160 [32]. Finally, Friedman et al. [37] showed that loss of $36 \%$ of initial bodyweight by gastric bypass surgery improved whole-body glucose disposal threefold and maximal glucose transport activity in vitro by $50 \%$ in three non-diabetic and four type 2 diabetic morbidly obese individuals with no effect on total GLUT-4 protein content in skeletal muscle biopsies. Collectively, these findings indicate that it is not

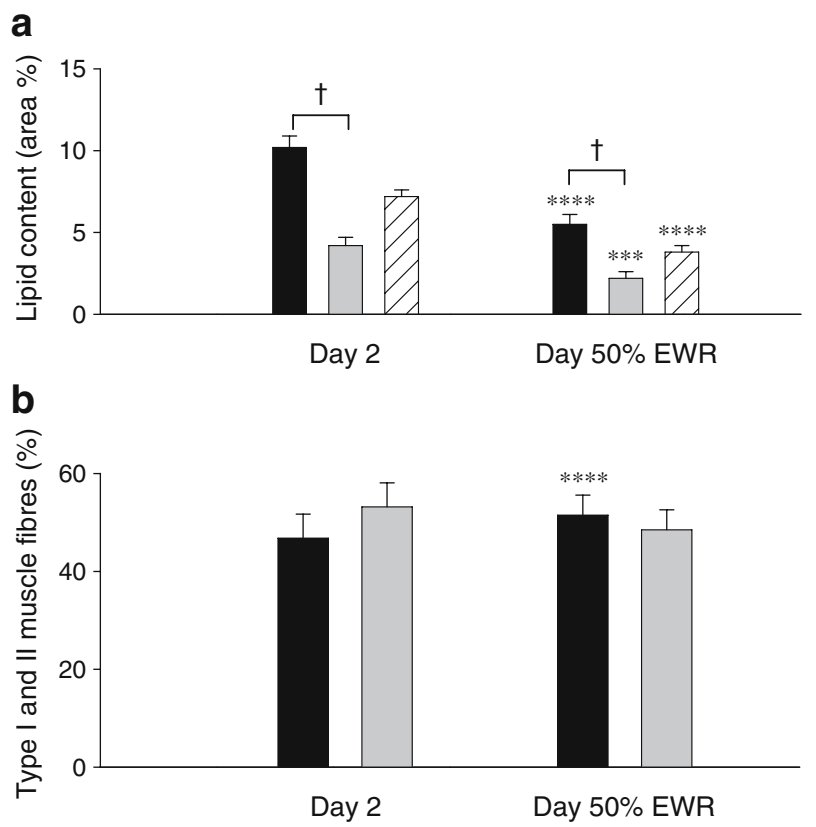

Fig. 5 a Quantification of the percentage IMCL in type I muscle fibres (black bars), type II muscle fibres (grey bars) and mean per cent IMCL (i.e. type I and II fibres combined, hatched bars) on day 2 of a VLED and at $50 \%$ EWR. Note the significant decrease in IMCL after weight loss in both fibre types. b The number of type I (black bars) and type II (grey bars) fibres on either study day. Note the significant increase in type I muscle fibres after weight loss. $* * * p<0.001, * * * * p<0.0001$ day 2 vs day of $50 \%$ EWR. ${ }^{\dagger} p<0.0001$ per cent IMCL in type I vs per cent IMCL in type 2 muscle fibres 
the amount of GLUT- 4 at the cell membrane but its function and, consequently, the velocity of glucose transport across the membrane that is quantitatively responsible for insulin-stimulated glucose disposal, as has been described previously [38]. Alternatively, another glucose transporter, either GLUT-1 [5] or a yet unidentified one, may have contributed to the increase in glucose uptake seen after weight loss. Another possible explanation is that insulin-stimulated glucose disposal in adipose tissue is greatly enhanced with weight loss.

It has been hypothesised that accumulation of IMCL metabolites is involved in the impaired insulin signalling via phosphorylation of IRS-1 and IRS-2 on serine residues, thereby rendering these serine-phosphorylated IRSs unable to associate with and activate PI3K [39]. In our study, substantial weight loss was associated with a significant decrease in IMCL, and the amount of IMCL on the day of $50 \%$ EWR correlated negatively with the glucose disposal rate. Indeed, other studies also revealed a similar association $[30,40]$. Rather than triacylglycerol itself, derivatives such as fatty acyl CoAs and diacylglycerol seem to be the causal factor for the development of insulin resistance [39]. Moreover, there is a potential link between the accumulation of these metabolites and the mitochondrial dysfunction that has been observed in type 2 diabetic patients and their offspring [39]. We did not measure mitochondrial density or ATP production but one expects that after weight loss due to ER, the organism has shifted to fatty acid betaoxidation rather than to glucose oxidation for muscle ATP production. This may have led to lower fatty acid concentrations in the sarcoplasma and thereby to improved insulin sensitivity. Clearly FAT/CD36 does not seem to be involved in the decrease in IMCL since sarcolemmal FAT/ CD36 content did not change with weight loss.

Patients with type 2 diabetes have a decreased percentage of type I (oxidative) muscle fibres and an increased percentage of type IIb (glycolytic) muscle fibres [41, 42]. Weight loss did not result in a significant increase in the percentage of type I muscle fibres in our study, which is consistent with that of all [43-45] but one other study [46]. Interestingly, like one other study [47], we also found a negative relationship between the amount of type I muscle fibres on day 2 and time to $50 \%$ EWR.

Whether the withdrawal of high doses of insulin has also played a role in the observed improvements in insulin sensitivity of liver, adipose tissue and muscle cannot be deduced from this study. In our short-term (2 day VLED) study we found no arguments for this [16, 17]. A study by Del Prato et al. shows that chronic (72-96 h) physiological hyperinsulinaemia impairs insulin sensitivity of the pancreas and muscle, not of the liver [48]. How long it takes to restore normal insulin sensitivity after cessation of hyperinsulinaemia is unknown. When a VLED and instituting insulin therapy were compared as therapy for type 2 diabetic patients on oral drug failure, both improved glucose levels but only a VLED improved insulin-stimulated glucose disposal [49]. So, it may very well be that the high doses of insulin used by our patients have contributed to their insulin resistance and that the withdrawal of this insulin played a role in the improvement in insulin sensitivity.

In conclusion, short-term energy restriction (2 day VLED) improves hyperglycaemia primarily via a decrease in EGP $[16,17]$. Moderate weight reduction (approximately $8 \mathrm{~kg}$ ) also improves hepatic insulin sensitivity [50], and substantial weight loss improves all aspects of glucose metabolism (this study). To the best of our knowledge this is the first study to show that weight loss improves insulin signal transduction, especially insulin-stimulated AS160 and PRAS40 phosphorylation. The large increase in insulin sensitivity in patients who were still obese and used no glucose-lowering medication again stresses the importance of weight-reducing approaches in the treatment of obese type 2 diabetic patients.

Acknowledgements The authors would like to thank I. Boesten for excellent technical help with GLUT-4 and FAT/CD36 immunoblotting assays; Nutrition \& Santé, Antwerp, Belgium for the free supply of Modifast; and Roba Metals (IJsselstein, the Netherlands) for financial support.

Duality of interest The authors declare that there is no duality of interest associated with this manuscript.

\section{References}

1. DeFronzo RA, Jacot E, Jequier E, Maeder E, Wahren J, Felber JP (1981) The effect of insulin on the disposal of intravenous glucose. Results from indirect calorimetry and hepatic and femoral venous catheterization. Diabetes 30:1000-1007

2. Bjornholm M, Kawano Y, Lehtihet M, Zierath JR (1997) Insulin receptor substrate-1 phosphorylation and phosphatidylinositol 3kinase activity in skeletal muscle from NIDDM subjects after in vivo insulin stimulation. Diabetes 46:524-527

3. Kim YB, Nikoulina SE, Ciaraldi TP, Henry RR, Kahn BB (1999) Normal insulin-dependent activation of Akt/protein kinase B, with diminished activation of phosphoinositide 3-kinase, in muscle in type 2 diabetes. J Clin Invest 104:733-741

4. Krook A, Bjornholm M, Galuska D et al (2000) Characterization of signal transduction and glucose transport in skeletal muscle from type 2 diabetic patients. Diabetes 49:284-292

5. Ryder JW, Yang J, Galuska D et al (2000) Use of a novel impermeable biotinylated photolabeling reagent to assess insulinand hypoxia-stimulated cell surface GLUT4 content in skeletal muscle from type 2 diabetic patients. Diabetes 49:647-654

6. Koistinen HA, Galuska D, Chibalin AV et al (2003) 5-Aminoimidazole carboxamide riboside increases glucose transport and cell-surface GLUT4 content in skeletal muscle from subjects with type 2 diabetes. Diabetes 52:1066-1072

7. Handberg A, Vaag A, Damsbo P, Beck-Nielsen H, Vinten J (1990) Expression of insulin regulatable glucose transporters in skeletal muscle from type 2 (non-insulin-dependent) diabetic patients. Diabetologia 33:625-627 
8. Pedersen O, Bak JF, Andersen PH et al (1990) Evidence against altered expression of GLUT1 or GLUT4 in skeletal muscle of patients with obesity or NIDDM. Diabetes 39:865-870

9. Beeson M, Sajan MP, Dizon M et al (2003) Activation of protein kinase C-zeta by insulin and phosphatidylinositol-3,4,5-( $\left(\mathrm{PO}_{4}\right)_{3}$ is defective in muscle in type 2 diabetes and impaired glucose tolerance: amelioration by rosiglitazone and exercise. Diabetes 52:1926-1934

10. Krook A, Roth RA, Jiang XJ, Zierath JR, Wallberg-Henriksson H (1998) Insulin-stimulated Akt kinase activity is reduced in skeletal muscle from NIDDM subjects. Diabetes 47:1281-1286

11. Brozinick JT Jr, Roberts BR, Dohm GL (2003) Defective signalling through Akt-2 and -3 but not Akt-1 in insulin-resistant human skeletal muscle: potential role in insulin resistance. Diabetes 52:935-941

12. Kane S, Sano H, Liu SC et al (2002) A method to identify serine kinase substrates. Akt phosphorylates a novel adipocyte protein with a Rab GTPase-activating protein (GAP) domain. J Biol Chem 277:22115-22118

13. Sano H, Kane S, Sano E et al (2003) Insulin-stimulated phosphorylation of a Rab GTPase-activating protein regulates GLUT4 translocation. J Biol Chem 278:14599-14602

14. Zeigerer A, McBrayer MK, McGraw TE (2004) Insulin stimulation of GLUT4 exocytosis, but not its inhibition of endocytosis, is dependent on RabGAP AS160. Mol Biol Cell 15:4406-4415

15. Karlsson HK, Zierath JR, Kane S, Krook A, Lienhard GE, Wallberg-Henriksson H (2005) Insulin-stimulated phosphorylation of the Akt substrate AS160 is impaired in skeletal muscle of type 2 diabetic subjects. Diabetes 54:1692-1697

16. Jazet IM, Pijl H, Frolich M, Romijn JA, Meinders AE (2005) Two days of a very low calorie diet reduces endogenous glucose production in obese type 2 diabetic patients despite the withdrawal of blood glucose lowering therapy, including insulin. Metabolism 54:705-712

17. Jazet IM, Ouwens DM, Schaart G et al (2005) Effect of a 2-day very low-energy diet on skeletal muscle insulin sensitivity in obese type 2 diabetic patients on insulin therapy. Metabolism 54:1669-1678

18. Simonson DC, DeFronzo RA (1999) Indirect calorimetry: methodological and interpretative problems. Am J Physiol 258: E399-E412

19. Gastaldelli A, Coggan AR, Wolfe RR (1999) Assessment of methods for improving tracer estimation of non-steady-state rate of appearance. J Appl Physiol 87:1813-1822

20. Hickey MS, Tanner CJ, O'Neill DS, Morgan LJ, Dohm GL, Houmard JA (1997) Insulin activation of phosphatidylinositol 3kinase in human skeletal muscle in vivo. J Appl Physiol 83:718-722

21. Ouwens DM, van der Zon GC, Pronk GJ et al (1994) A mutant insulin receptor induces formation of a Shc-growth factor receptor bound protein 2 (Grb2) complex and p21ras-GTP without detectable interaction of insulin receptor substrate 1 (IRS1) with Grb2. Evidence for IRS1-independent p21ras-GTP formation. J Biol Chem 269:33116-33122

22. Roorda BD, Hesselink MK, Schaart G et al (2005) DGAT1 overexpression in muscle by in vivo DNA electroporation increases intramyocellular lipid content. J Lipid Res 46:230-236

23. Borghouts LB, Schaart G, Hesselink MK, Keizer HA (2000) GLUT-4 expression is not consistently higher in type-1 than in type-2 fibres of rat and human vastus lateralis muscles; an immunohistochemical study. Pflugers Arch 441:351-358

24. Keizer HA, Schaart G, Tandon NN, Glatz JF, Luiken JJ (2004) Subcellular immunolocalisation of fatty acid translocase (FAT)/ CD36 in human type-1 and type-2 skeletal muscle fibers. Histochem Cell Biol 121:101-107

25. Steele R (1959) Influences of glucose loading and of injected insulin on hepatic glucose output. Ann NY Acad Sci 82:420-430

26. DeFronzo RA, Ferrannini E, Simonson DC (1989) Fasting hyperglycemia in non-insulin dependent diabetes mellitus: contributions of excessive glucose production and impaired glucose uptake. Metabolism 38:387-395
27. Groop LC, Bonadonna RC, DelPrato S et al (1989) Glucose and free fatty acid metabolism in non-insulin-dependent diabetes mellitus. Evidence for multiple sites of insulin resistance. J Clin Invest 84:205-213

28. Elahi D, Nagulesparan M, Hershcopf RJ et al (1982) Feedback inhibition of insulin secretion by insulin: relation to the hyperinsulinemia of obesity. N Engl J Med 306:1196-1202

29. Pereira JA, Lazarin MA, Pareja JC, de Souza A, Muscelli E (2003) Insulin resistance in nondiabetic morbidly obese patients: effect of bariatric surgery. Obes Res 11:1495-1501

30. Fabris R, Mingrone G, Milan G et al (2004) Further lowering of muscle lipid oxidative capacity in obese subjects after biliopancreatic diversion. J Clin Endocrinol Metab 89:1753-1759

31. Meyer MM, Levin K, Grimmsmann T et al (2002) Troglitazone treatment increases protein kinase B phosphorylation in skeletal muscle of normoglycemic subjects at risk for the development of type 2 diabetes. Diabetes 51:2691-2697

32. Karlsson HK, Hallsten K, Bjornholm M et al (2005) Effects of metformin and rosiglitazone treatment on insulin signalling and glucose uptake in patients with newly diagnosed type 2 diabetes: a randomized controlled study. Diabetes 54:1459-1467

33. Christ-Roberts CY, Pratipanawatr T, Pratipanawatr W et al (2004) Exercise training increases glycogen synthase activity and GLUT4 expression but not insulin signaling in overweight nondiabetic and type 2 diabetic subjects. Metabolism 53:1233-1242

34. Dann SG, Selvaraj A, Thomas G (2007) mTOR Complex-1-S6K1 signalling: at the crossroads of obesity, diabetes and cancer. Trends Mol Med 13:252-259

35. Manning BD, Cantley LC (2007) AKT/PKB signaling: navigating downstream. Cell 129:1261-1274

36. Nascimento EB, Fodor M, van der Zon GC et al (2006) Insulinmediated phosphorylation of the proline-rich Akt substrate PRAS40 is impaired in insulin target tissues of high-fat diet-fed rats. Diabetes 55:3221-3228

37. Friedman JE, Dohm GL, Leggett-Frazier N et al (1992) Restoration of insulin responsiveness in skeletal muscle of morbidly obese patients after weight loss. Effect on muscle glucose transport and glucose transporter GLUT4. J Clin Invest 89:701-705

38. Furtado LM, Somwar R, Sweeney G, Niu W, Klip A (2002) Activation of the glucose transporter GLUT4 by insulin. Biochem Cell Biol 80:569-578

39. Morino K, Petersen KF, Shulman GI (2006) Molecular mechanisms of insulin resistance in humans and their potential links with mitochondrial dysfunction. Diabetes 55(Suppl 2):S9-S15

40. Greco AV, Mingrone G, Giancaterini A et al (2002) Insulin resistance in morbid obesity: reversal with intramyocellular fat depletion. Diabetes 51:144-151

41. Hickey MS, Carey JO, Azevedo JL et al (1995) Skeletal muscle fiber composition is related to adiposity and in vitro glucose transport rate in humans. Am J Physiol 268:E453-E457

42. Marin P, Andersson B, Krotkiewski M, Bjorntorp P (1994) Muscle fiber composition and capillary density in women and men with NIDDM. Diabetes Care 17:382-386

43. Gray RE, Tanner CJ, Pories WJ, MacDonald KG, Houmard JA (2003) Effect of weight loss on muscle lipid content in morbidly obese subjects. Am J Physiol Endocrinol Metab 284:E726-E732

44. Kern PA, Simsolo RB, Fournier M (1999) Effect of weight loss on muscle fiber type, fiber size, capillarity, and succinate dehydrogenase activity in humans. J Clin Endocrinol Metab 84:4185-4190

45. Kempen KP, Saris WH, Kuipers H, Glatz JF, Van Der Vusse GJ (1998) Skeletal muscle metabolic characteristics before and after energy restriction in human obesity: fibre type, enzymatic betaoxidative capacity and fatty acid-binding protein content. Eur J Clin Invest 28:1030-1037

46. Niskanen L, Uusitupa M, Sarlund H, Siitonen O, Paljarvi L, Laakso M (1996) The effects of weight loss on insulin sensitivity, 
skeletal muscle composition and capillary density in obese nondiabetic subjects. Int J Obes Relat Metab Disord 20:154-160

47. Tanner CJ, Barakat HA, Dohm GL et al (2002) Muscle fiber type is associated with obesity and weight loss. Am J Physiol Endocrinol Metab 282:E1191-E1196

48. Del Prato S, Leonetti F, Simonson DC, Sheehan P, Matsuda M, DeFronzo RA (1994) Effect of sustained physiologic hyperinsulinaemia and hyperglycaemia on insulin secretion and insulin sensitivity in man. Diabetologia 37:1025-1035
49. Laakso M, Uusitupa M, Takala J, Majander H, Reijonen T, Penttila I (1988) Effects of hypocaloric diet and insulin therapy on metabolic control and mechanisms of hyperglycemia in obese non-insulin-dependent diabetic subjects. Metabolism 37: 1092-1100

50. Petersen KF, Dufour S, Befroy D, Lehrke M, Hendler RE, Shulman GI (2005) Reversal of nonalcoholic hepatic steatosis, hepatic insulin resistance, and hyperglycemia by moderate weight reduction in patients with type 2 diabetes. Diabetes 54:603-608 